\title{
Cerebrospinal fluid findings in adults with acute Lyme neuroborreliosis
}

\author{
Marija Djukic • Carsten Schmidt-Samoa • \\ Peter Lange • Annette Spreer - Katja Neubieser • \\ Helmut Eiffert $\cdot$ Roland Nau $\cdot$ Holger Schmidt
}

Received: 7 May 2011/Revised: 6 August 2011/Accepted: 10 August 2011/Published online: 6 September 2011

(C) The Author(s) 2011. This article is published with open access at Springerlink.com

\begin{abstract}
Presence of $B B$-specific antibodies in the cerebrospinal fluid (CSF) with evidence of their intrathecal production in conjunction with the white cell count in the CSF and typical clinical symptoms is the traditional diagnostic gold standard of Lyme neuroborreliosis (LNB). Few data are available on the CSF lactate concentration in European adults with the diagnosis of acute LNB. The objective of the study was to investigate the CSF changes during acute LNB. Routine CSF parameters [leukocyte count, protein, lactate and albumin concentrations, $\mathrm{CSF} /$ serum quotients of albumin $\left(\mathrm{Q}_{\mathrm{Alb}}\right), \operatorname{IgG}, \operatorname{IgA}$ and $\operatorname{IgM}$, and oligoclonal IgG bands] and the Borrelia burgdorferi $(B B)$ specific antibody index were retrospectively studied in relation to the clinical presentation in patients diagnosed
\end{abstract}

M. Djukic and C. Schmidt-Samoa contributed equally to this work.

M. Djukic $(\bowtie) \cdot R$. Nau

Department of Geriatrics, Evangelisches Krankenhaus

Goettingen-Weende, An der Lutter 24, 37075 Goettingen, Germany

e-mail: mdjukic@gwdg.de

C. Schmidt-Samoa - P. Lange - A. Spreer - K. Neubieser .

H. Schmidt

Department of Neurology, University Medical Center

Goettingen, Robert-Koch-Str. 40, 37075 Goettingen, Germany

H. Eiffert

Medical Microbiology, University Medical Center Goettingen, Kreuzbergring 57, 37075 Goettingen, Germany

R. Nau

Department of Neuropathology, University Medical Center Goettingen, Robert-Koch-Str. 40, 37075 Goettingen, Germany with acute LNB. A total of 118 patients with LNB were categorized into the following groups according to their symptoms at presentation; group 1: polyradiculoneuritis (Bannwarth's syndrome), group 2: isolated facial palsy and group 3: predominantly meningitic course of the disease. In addition to the CSF of patients with acute LNB, CSF of 19 patients with viral meningitis (VM) and 3 with neurolues (NL) were analyzed. There were 97 patients classified with definite LNB, and 21 as probable LNB. Neck stiffness and fever were reported by $15.3 \%$ of patients. Most of these patients were younger than 50 years. Polyradiculoneuritis was frequently found in patients older than 50 years. Lymphopleocytosis was found in all patients. Only 5 patients had a CSF lactate $\geq 3.5 \mathrm{mmol} / \mathrm{l}$, and the mean CSF lactate level was not elevated $(2.1 \pm 0.6 \mathrm{mmol} / \mathrm{l})$. The patients with definite LNB had significantly higher lactate levels than patients with probable LNB. Elevated lactate levels were accompanied by fever and headache. In the Reiber nomograms, intrathecal immunoglobulin synthesis was found for IgM in $70.2 \%$ followed by $\operatorname{IgG}$ in $19.5 \%$. Isoelectric focussing detected an intrathecal IgG synthesis in 83 patients $(70.3 \%)$. Elevated $B B$ AIs in the CSF were found in 97 patients $(82.2 \%)$. Patients with VM showed lower CSF protein concentration and CSF/serum quotients of albumin than LNB patients. In acute LNB, all patients had elevated cerebrospinal fluid (CSF) leukocyte counts. In contrast to infections by other bacteria, CSF lactate was lower than $3.5 \mathrm{mmol} / \mathrm{l}$ in all but 5 patients. The CSF findings did not differ between polyradiculoneuritis, facial palsy, and meningitis. The CSF in LNB patients strongly differed from CSF in VM patients with respect to protein concentration and the CSF/serum albumin quotient.

Keywords Acute lyme neuroborreliosis - CSF findings . Clinical symptoms 


\section{Introduction}

Lyme neuroborreliosis (LNB) is the neurological manifestation of systemic infection caused by the spirochete Borrelia burgdorferi $(B B)$ sensu lato. Clinical features of LNB are diverse and differ in European and American patients-most probably because of variations in the Borrelia species [1,2].

The diagnosis of LNB is based on a combination of history, clinical examination, analysis of cerebrospinal fluid (CSF), and the detection of antibodies against $B B$ in serum and CSF.

According to the criteria of the German Society of Neurology (DGN) LNB is probable when typical clinical symptoms, pleocytosis in the CSF, and positive serum tests for Borrelia-specific IgG or IgM are present [3]. The detection of intrathecal synthesis of specific anti-Borrelia antibodies is considered necessary to diagnose definite LNB in Germany and other European countries [1, 3, 4], whereas American criteria do not require an elevated antiBorrelia antibody index (AI) [5, 6].

Laboratory confirmation of LNB is hampered by the low sensitivity of culture and polymerase chain reaction (PCR) in CSF [7]. Presence of $B B$-specific antibodies in the CSF with evidence of intrathecal production is the traditional diagnostic gold standard but has limitations such as low sensitivity in the very early phase of the disease $[1,2,4]$ and can persist for years after eradication of the infection $[8,9]$. In recent years, the B lymphocyte chemoattractant chemokine CLCX13 has been identified as a potentially important biomarker for the diagnosis of acute LNB [10, 11]. Reported sensitivities and specificities are high (in a similar range as for AIs), suggesting that CSF CLCX13 might be a useful addition to the diagnostic armamentarium, especially in the very early stage of LNB, where AIs might still be negative. However, as patient numbers in the published studies are rather low, further corroboration of these results is needed. Several other, more or less validated laboratory tests have been developed to improve diagnosis. Few data are available on the CSF lactate levels in adults with definite acute LNB. The aim of this study was to evaluate CSF changes in patients with acute LNB.

\section{Methods}

Patients

All files of patients who were coded as "probable" or "definite" acute LNB upon admission to the Neurological Department of the University Medical Center Goettingen during the past 14 years were screened. The diagnosis of acute LNB was made if in addition to the typical neurological symptoms and CSF lymphopleocytosis, either IgM or IgG antibodies for $B B$ were identified in serum and/or CSF. Only patients $\geq 16$ years of age who had received a lumbar puncture and with a sufficient clinical documentation were eligible for this investigation. Exclusion criteria were other putative reasons for inflammation in the central nervous system (CNS) at presentation. Files were screened for a study on long-term outcome of patients after acute NB.

To compare the CSF findings of patients with LNB to CSF findings of patients with CSF pleocytosis of other origins, files of patients with viral meningitis (VM) $(n=19)$ and neurolues (NL) were also screened. Moreover, all files of patients with NL without concomitant HIV infection from the last 10 years were included.

The study was approved by the local ethics committee.

\section{Clinical examination}

For clinical symptoms, we applied the Scripps Neurological Rating Scale (SNRS) [12], which met our needs for thorough documentation and reproducibility. In addition, age, fever, number of days from the onset of symptoms to hospitalization, information on tick bites, and erythema migrans (EM) were registered.

LNB patients were categorized into the following groups according to their symptoms at presentation: group 1 -polyradiculoneuritis (Bannwarth's syndrome), group 2-isolated facial palsy, group 3-predominantly meningitic course of the disease.

\section{Laboratory tests}

IgM and $\operatorname{IgG}$ antibody response to antigens of $B B$ was determined in serum by sandwich enzyme-linked immunosorbent assays (ELISA) according to the instructions of the manufacturer (Genzyme Virotech, Rüsselsheim, Germany). The IgM ELISA was based on antigens of Borrelia afzelii (analytical sensitivity 99\%, specificity 98.8\%, manufacturer's information). The antigens of the $\mathrm{IgG}$ ELISA were Borrelia afzelii lysate plus VlsE (analytical sensitivity $99 \%$, specificity $97 \%$, manufacturer's information). In patients with a positive ELISA response, Western blots (Borrelia line, Genzyme Virotech, Rüsselsheim, Germany) were performed to confirm the specificity of the antibodies [13]. The antigens investigated were OspC, VlsE, BmpA, and DbpA for the detection of specific antibodies (analytical sensitivity 99\%, specificity 98\%, manufacturer's information).

The CSF was examined for leukocyte count (pleocytosis defined as $>4$ leukocytes $/ \mu l$ ), levels of protein, albumin, and lactate (pathological $\geq 2.1 \mathrm{mmol} / \mathrm{l}$ ). Intrathecal 
concentrations of $\operatorname{IgG}, \operatorname{Ig} \mathrm{A}$, and $\operatorname{IgM}$ were measured immunonephelometrically, and the CSF/serum ratios of $\mathrm{IgG}$, $\operatorname{IgA}, \operatorname{IgM}$, and albumin were calculated. $\operatorname{IgG}$, IgA, and $\operatorname{IgM}$ ratios were plotted versus albumin ratios according to the nomogram of Reiber and Felgenhauer [14].

The presence of an intrathecal production of $B B$-specific antibodies was evaluated by calculation of the $B B$-specific antibody index (AI). For this purpose, a modified immonoassay was used, based on the commercially available immunoassay plates Enzygnost Borreliosis $\mathrm{IgG} / \mathrm{IgM}$ of Siemens Healthcare Diagnostics GmbH, Marburg, Germany. To increase the sensitivity, the secondary antibodies supplied with the test kit were replaced by anti-IgG or anti-IgM antibodies from DAKO, Hamburg, Germany. Arbitrary concentration units were calculated based on a standard curve derived from seven 2-fold serial dilutions of a positive standard serum pool to fit an absorbance range of 0.05-2.0. The highest standard concentration (absorption of approximately 2.0) was defined as 100 arbitrary units. CSF and serum pairs of every patient had to be analyzed on the same plate, and the CSF and serum sample were diluted to yield antibody concentrations that were in similar parts of the standard curve. Therefore, standard predilution ratios were 1:30 for CSF and 1:6000 for serum, in case of an intrathecal immunoglobulin production modified predilution ratios were used. Only those extinctions were used for AI calculation that lay more than 0.1 above the blank sample and within the simultaneously determined standard curve.

The AI was calculated according to the formula $\left(\operatorname{Ig}_{\mathrm{CSF} B B} / \operatorname{Ig}_{\text {serum } B B}\right) /\left(\operatorname{Ig}_{\mathrm{CSF} \text { total }} / \operatorname{Ig}_{\text {serum total }}\right)$. In case of an overall IgG or IgM synthesis detected by the ReiberFelgenhauer nomograms, the denominator $\operatorname{Ig}_{\mathrm{CSF}}$ total Ig $_{\text {serum total }}$ is replaced by Qlim. Qlim is the maximum ratio of $\mathrm{Ig}_{\mathrm{CSF} \text { total }} / \mathrm{Ig}_{\text {serum total }}$ which can be expected at a given $\mathrm{CSF} / \mathrm{serum}$ albumin ratio in the absence of intrathecal immunoglobulin synthesis (mean +3 standard deviations) $[15,16]$. The AI was defined as pathologic (i.e., indicative of a synthesis of antibodies against $B B$ antigen within the CNS), when it was $\geq 1.5$.

Isoelectric focusing was used to detect oligoclonal intrathecal IgG synthesis [14]. The CSF findings were compared between groups.

\section{Statistics}

Statistical calculations were performed with GraphPad Prism software (GraphPad Software, La Jolla, CA, USA). Data was described by median and interquartile range. To prove whether our values were normally distributed the D'Agostino-Pearson normality test was used. For univariate analyses, we used $t$ test of independent samples for normally distributed data and $U$ test in the absence of normal distribution. For the comparison of more than two groups, we used ANOVA or ANOVA on ranks depending on the distribution of the original data. Contingency tables were use to analyze the relation of two variables in the groups of patients younger or older than 50 years, and statistical significance was assessed by Fisher's exact test. Correlations (for parametric data Pearson's correlation coefficient $r$, for non-parametric data Spearman's rank correlation coefficient $r_{\mathrm{s}}$ ) between different parameters were also analyzed. $P$ values $\leq 0.05$ were considered statistically significant.

\section{Results}

Clinical, CSF, and serological findings

In 118 patients, acute LNB was diagnosed, of which 21 were grouped as probable $\mathrm{LNB}(\mathrm{AI}<1.5$ or not performed) and 97 as definite $\mathrm{LNB}(\mathrm{AI} \geq 1.5)$. The mean age of all patients was $50 \pm 17.1$ years and the gender ratio was $40 / 78(\mathrm{~F} / \mathrm{M})$.

In the cohort, $15.3 \%$ of patients presented with headache and fever. Sixteen of these patients were younger than 50 years $(34.6 \pm 11.2$ years). Patients with headache and fever displayed more often neck stiffness $(n=18)$ than patients with polyradiculitis (5 out of 53) $(p=0.015)$. Polyradiculitis was frequently found in patients older than 50 years (age $54.1 \pm 15.1$ years). The frequency of facial palsy was not significantly different in patients younger $(n=28)$ and older than 50 years $(n=19)$, respectively, $(p=0.4)$. One patient presented with stroke, one with paresis of N. abducens, one with an epileptic seizure, and two with vertigo.

Clinical symptoms and CSF parameters of the different groups are summarized in Table 1 and Fig. 1.

Only 5 patients with LNB showed CSF lactate concentrations $\geq 3.5 \mathrm{mmol} / \mathrm{l}$, and the mean CSF lactate concentration was not elevated $(2.1 \pm 0.6 \mathrm{mmol} / \mathrm{l})$. The mean CSF lactate levels of patients with definite LNB $(2.3 \pm 0.7 \mathrm{mmol} / \mathrm{l})$ were slightly but significantly higher $(p=0.002)$ than the mean CSF lactate levels of patients with probable LNB $(1.8 \pm 0.3 \mathrm{mmol} / \mathrm{l})$. Patients with elevated lactate levels $(\geq 2.1 \mathrm{mmol} / \mathrm{l})$ [(group $1-32.1 \%$; group 2-46.8\%; group 3-55.6\%), $n=49$ ] presented significantly more often with fever and headache $(n=43$; Fisher's exact test $p=0.02$ ).

Elevated $B B$ AIs in CSF were found in 97 patients (82.2\%). $B B$ IgM AIs were elevated in 72 patients and $B B$ IgG AIs in 82 patients. Of the 23 patients pre-treated with antibiotics, 15 patients had elevated $B B$ AIs (65.2\%) in CSF. Symptoms developed in 107 patients within 6 weeks. The $B B$ AIs of 21 patients were $<1.5$ (17.8\%). Eleven 
Table 1 Comparison of laboratory parameters between patients with polyradiculoneuritis (group 1), facial palsy (group 2), and patients with a meningitic course of LNB (group 3)

\begin{tabular}{llll}
\hline Parameter & $\begin{array}{l}\text { Polyradiculoneuritis }(n=53) \\
\text { age }(54.8 \pm 15.2)\end{array}$ & $\begin{array}{l}\text { Facial palsy }(n=47) \\
\text { age }(45.9 \pm 18.5)\end{array}$ & $\begin{array}{l}\text { Meningitic course }(n=18) \\
\text { age }(34.6 \pm 11.2)\end{array}$ \\
\hline CSF leukocytes $\left[\mu 1^{-1}\right]$ & $171.5(54.5 ; 354)$ & $210.5(90.3 ; 411.8)$ & $345.5(100.8 ; 543.3)$ \\
CSF protein $[\mathrm{mg} / 1]$ & $1,339(779 ; 2,087)$ & $1,372(887 ; 2,003)$ & $942(553.0 ; 1,543)$ \\
QAlbumin $\times 10^{-3}$ & $19.8(9.8 ; 31.7)$ & $21.0(12.0 ; 28.4)$ & $12.6(8.1 ; 23.3)$ \\
CSF lactate $[\mathrm{mmol} / 1]$ & $2.0(1.7 ; 2.6)$ & $2.0(1.7 ; 2.6)$ & $2.4(1.8 ; 2.9)$ \\
\hline
\end{tabular}

Descriptive values are median and interquartile range $\left(\mathrm{Q}_{25}\right.$ and $\left.\mathrm{Q}_{75}\right)$. After using the D'Agostino-Pearson normality test, the Kruskal-Wallis test was used for statistical comparisons of not normally distributed data (cell count, protein level, and $\mathrm{Q}_{\text {Albumin }}$ ). ANOVA was used for statistic analysis of normally distributed data (lactate concentration). Between the groups, we could not find any significant differences

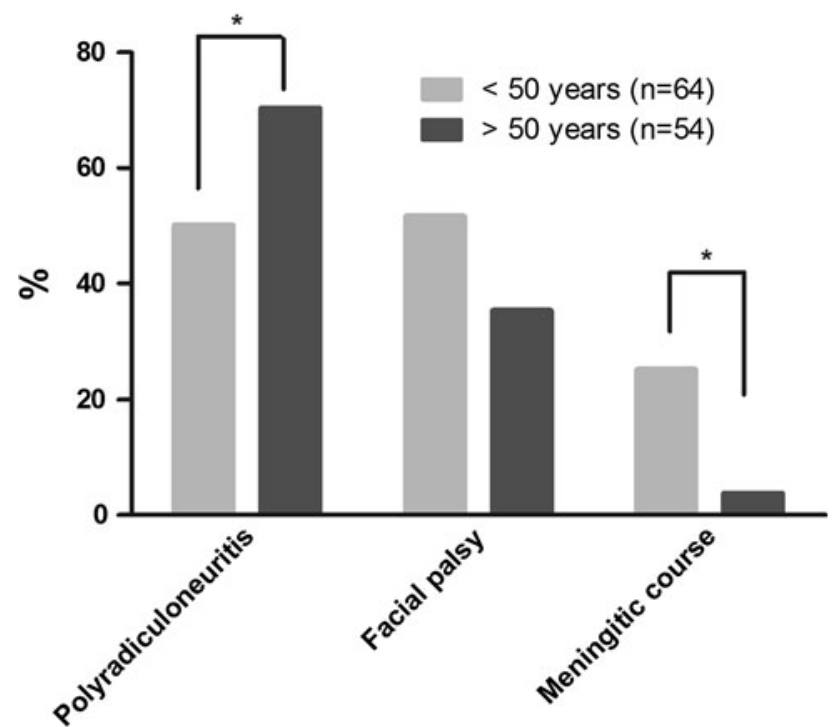

Fig. 1 Symptoms in patients younger versus patients older than 50 years. Polyradiculoneuritis was significantly more frequent in patients older than 50 years. In contrast, a meningitic course of the disease was more common in patients under 50 years

patients reported symptoms for 6 weeks or longer prior to lumbar puncture. Of these patients, 10 had elevated $B B$ AIs (90.9\%).

Intrathecal immunoglobulin synthesis as estimated by Reiber-Felgenhauer nomogram was found for $\operatorname{IgM}$ in $70.2 \%$, followed by $\operatorname{IgG}$ in $19.5 \%$. Intrathecal synthesis of $\mathrm{IgM}, \operatorname{IgG}$, and $\operatorname{IgA}$ was found in 11 patients.

Isoelectric focussing, more sensitive than the ReiberFelgenhauer plots, detected oligoclonal IgG bands indicating IgG synthesis in the CSF in 83 patients (70.3\%). The positive oligoclonal IgG bands were significantly more frequent in patients with polyradiculoneuritis and facial palsy than in patients with a meningitic course of acute LNB. This may be a sign of stronger immune responses in these patients. The differences of $B B$-specific AIs and oligoclonal bands between the groups are summarized in Table 2 .
Table 2 Numbers of patients with positive oligoclonal IgG bands in $\mathrm{CSF}$ and $B B$-specific antibody index (AI) in 118 patients diagnosed with acute LNB

\begin{tabular}{lllll}
\hline Parameter & $\begin{array}{l}\text { Polyradiculoneuritis } \\
(n=53)\end{array}$ & $\begin{array}{l}\text { Facial } \\
\text { palsy } \\
(n=47)\end{array}$ & $\begin{array}{l}\text { Meningitic } \\
\text { course } \\
(n=18)\end{array}$ & $P$ \\
\hline $\begin{array}{c}\text { Positive } \\
\text { oligoclonal }\end{array}$ & 40 & 35 & 8 & $0.03^{*}$ \\
$\quad \begin{array}{l}\text { IgG bands } \\
\text { Positive } B B \\
\text { AI IgG }\end{array}$ & 45 & 37 & 11 & 0.10 \\
$\begin{array}{c}\text { Positive } B B \\
\text { AI IgM }\end{array}$ & 39 & 34 & 9 & 0.15 \\
\hline
\end{tabular}

Group 1 represents patients with polyradiculoneuritis, group 2 patients with facial palsy and group 3 patients with a meningitic course of acute LNB. Positive oligoclonal IgG bands were significantly more frequent in patients with polyradiculoneuritis and facial palsy (Chi square test)

Neurolues (NL) was diagnosed during the last 10 years in only 6 patients in our department. Three of them had concomitant HIV encephalitis. The CSF samples of the remaining 3 patients with isolated neurolues were analyzed. All 3 patients were male $(100 \%)$. The mean age of patients with NL was $46.2 \pm 13.8$ years.

Nineteen patients were allocated to the VM group. The mean age was $38.3 \pm 17.3$ years, 8 of them were male (42\%). The CSF findings of patients with acute LNB, VM, and NL are summarized in the Table 3. The statistical analysis between these three groups was not possible, because of the low number of patients with NL; however, the statistical comparison between LNB patients and VM patients was performed.

Of the 95 patients in which serum antibodies against $B B$ were determined quantitatively, $B B$ - specific IgM concentrations were above the cut-off in $68(71.6 \%)$ patients; 60 patients $(76.9 \%)$ had elevated anti- $B B$ IgG concentrations in serum. $B B$-specific $\operatorname{IgM}$ and $\operatorname{IgG}$ concentrations below the cut-off of the ELISA in serum were found in 12 
Table 3 CSF finding in patients with acute lyme neuroborreliosis (LNB), viral meningitis (VM) and neurolues (NL)

\begin{tabular}{llll}
\hline Parameter & LNB $(n=118)$ age $(50 \pm 17.1)$ & VM $(n=19)$ age $(38.3 \pm 17.3)$ & NL $(n=3)$ age $(46.2 \pm 13.8)$ \\
\hline CSF leukocytes $\left[\mu 1^{-1}\right]$ & $170.5(57.0 ; 369)$ & $97.0(21.0 ; 210.0)$ & $65(7.0 ; 100.7)$ \\
CSF protein $[\mathrm{mg} / \mathrm{l}]$ & $1,232(697 ; 1,926)$ & $628(493.0 ; 969)^{*}$ & $614(328.0 ; 800.0)$ \\
Q Albumin $\times 10^{3}$ & $17.2(9.7 ; 28.4)$ & $9.1(7.2 ; 14.7)^{*}$ & $7.6(4.0 ; 11.7)$ \\
CSF lactate $[\mathrm{mmol} / \mathrm{l}]$ & $2.0(1.6 ; 2.6)$ & $2.1(1.9 ; 2.3)$ & $1.5(1.3 ; 1.6)$
\end{tabular}

Descriptive values are median and interquartile range $\left(\mathrm{Q}_{25}\right.$ and $\left.\mathrm{Q}_{75}\right)$

$* p \leq 0.05$ LNB versus VM (Mann-Whitney $U$ test)

patients. Of these 12 patients, 9 had positive $B B$ AI IgM, $B B$ AI $\operatorname{IgG}$, or both in CSF.

In the remaining 23 patients, blood samples were not tested for antibodies against $B B$ in a separate quantitative test, as definite evidence for acute LNB had been established previously by typical clinical signs and positive AI against $B B$ for $\operatorname{IgG}$, IgM, or both in CSF and serum samples measured simultaneously in the same assay.

Serum CRP was measured in 81 patients, and elevated levels were found in 11. WBC was measured in all patients; 14 patients showed leukocytosis $(\geq 11,000 / \mu \mathrm{l})$. Between the different clinical presentations, we could not find significant differences for these laboratory parameters.

\section{Discussion}

European LNB is associated with elevated cell count in the CSF, typically 10-1,000 leukocytes $/ \mathrm{mm}^{3}(60 \%$ between 30 and 300 cells $/ \mathrm{mm}^{3}$ ), mainly B lymphocytes and plasma cells. Together with the intrathecal immunoglobulin production with intrathecal $\operatorname{IgM}$ dominance and blood-CSF barrier dysfunction, these typical CSF changes allow the diagnosis of acute LNB with a specificity of $96 \%$ and sensitivity of $70 \%$ [17]. Published data compare well with our findings of intrathecal $\operatorname{IgM}$ synthesis in $70.2 \%$ of the patients and lymphopleocytosis in all patients. The diagnostic sensitivity of $B B$-specific antibody production in CSF is about $80 \%$ [18]. In our study, the sensitivity of the elevated $B B$-specific antibody index was $82.2 \%$.

A positive AI may persist for years after successful therapy $[8,9]$. In some cases, the AIs were $\geq 1.5$ while in serum $B B$-specific antibodies were below the cut-off of the ELISA [19]. This phenomenon was found in 9 patients in our study.

After effective treatment of LNB, $B B$-specific antibodies concentrations frequently decrease more rapidly in serum than in the CSF. This can lead to an increased AI during recovery.

$B B$ AI negativity in CSF in patients with early LNB has been documented in series of patients with LNB confirmed by culture, PCR, or $B B$ antigen demonstration [20, 21]. The frequency of $18.7 \% \mathrm{BB}$ AI negativity in our patients with symptoms lasting $<6$ weeks is in accordance with frequencies of 10-20\% early $B B$ AI negativity reported from other European centers $[15,17,22]$. These findings confirm that $B B$ AIs in the acute phase of LNB have only moderate sensitivity.

Early antibiotic therapy can abort the humoral immune response resulting in undetectable or normal $B B$ AI or may impede the immune switch from IgM to IgG in plasma [23, 24]. On the other hand, one study showed an increased percentage of B cells in CSF and of intrathecally produced $B B$ antibodies immediately after initiation of antibiotic treatment [25]. Our data demonstrate the necessity to determine the AIs both for $B B \operatorname{IgM}$ and IgG.

Patients with LNB with normal leukocyte counts have been described exceptionally. These patients were either in the very early stage of the disease or were immunosuppressed individuals or were children with an isolated facial palsy [19]. In our study, all patients had CSF lymphopleocytosis, and we have not seen such a case in adults during our clinical practise.

Studies which investigated the role of CSF lactate levels for diagnosis of LNB are very rare. For other types of bacterial meningitis, such as pneumococcal or meningococcal meningitis, a CSF lactate level $\geq 3.5 \mathrm{mmol} / \mathrm{l}$ is typical and found in $90 \%$ of patients during the acute stage [17]. In our study, a normal mean CSF lactate level was found for all patients. However, patients with definite LNB showed slightly elevated CSF lactate concentrations compared to the patients with probable LNB. All 5 LNB patients with CSF lactate levels $\geq 3.5 \mathrm{mmol} / 1$ had a meningitic course of the diseases. Elevated lactate levels were significantly more often accompanied by fever and headache. With respect to the CSF abnormalities, the most difficult differential diagnosis of LNB is tuberculous meningitis. The typical CSF changes during tuberculous meningitis are lymphopleocytosis $(80 \%$ between 30 and 300 cells $/ \mathrm{mm}^{3}$ ), severe blood-CSF barrier dysfunction and predominant intrathecal $\operatorname{IgA}$ synthesis. In contrast to LNB, patients with neurotuberculosis in general show CSF lactate levels $\geq 3.5 \mathrm{mmol} / 1$ [17]. 
The most common neurological manifestation of LNB in Europe in adults is polyradiculoneuritis (Bannwarth's syndrome) [26]. In our population polyradiculoneuritis was also the predominant syndrome which could be found significantly more frequently in patients older than 50 years. During LNB headache occurs in about $40 \%$, but headache as the prominent symptom without (pseudo) radicular pain or paresis, i.e., a meningitic syndrome, is rare in adults [27]. In our study, isolated headache and neck stiffness was observed in $15.2 \%$ of patients younger and in 5 patients older than 50 years. These were the patients in whom fever and elevated lactate concentrations were also measured. In another study, headache and stiff neck was found in $13 \%$ of patients but differences in clinical manifestation and age of patients were not considered [28]. To our knowledge, this is the first study investigating the influence of age on clinical manifestation in an adult patient cohort with definite and probable LNB.

In conclusion, acute LNB is a clinical diagnosis supported by characteristic CSF abnormalities, in particular elevated CSF leukocyte counts, blood-CSF barrier dysfunction, predominant intrathecal IgM synthesis and elevated $B B$-specific AI for IgM or IgG. In contrast to other forms of bacterial meningitis, the mean CSF lactate level in our study was not elevated. Lactate can provide rapid and reliable information, in particular, with respect to the differential diagnosis tuberculous meningitis. Therefore, we recommend routine measurement of CSF lactate in adults with suspected acute LNB. Lactate is unsuitable for the differentiation of LNB and VM; CSF protein content and the CSF/serum albumin quotient are more appropriate.

\section{Conflict of interest None.}

Open Access This article is distributed under the terms of the Creative Commons Attribution Noncommercial License which permits any noncommercial use, distribution, and reproduction in any medium, provided the original author(s) and source are credited.

\section{References}

1. Hansen K, Lebech AM (1992) The clinical and epidemiological profile of Lyme neuroborreliosis in Denmark 1985-1990. A prospective study of 187 patients with Borrelia burgdorferi specific intrathecal antibody production. Brain 115:399-423. doi: 10.1093/brain/115.2.399

2. Ljostad U, Skarpaas T, Mygland A (2007) Clinical usefulness of intrathecal antibody testing in acute Lyme neuroborreliosis. Eur J Neurol 14:873-876. doi:10.1111/j.1468-1331.2007.01799.x

3. Rauer S (2008) Neuroboreliose. In: Diener HC, Putzki N (eds) Leitlinien für die diagnostik und therapie in der neurologie, 3rd edn. Georg Thieme Verlag, Stuttgart, pp 415-423

4. Blanc F, Jaulhac B, Fleury M et al (2007) Relevance of the antibody index to diagnose Lyme neuroborreliosis among seropositive patients. Neurology 69:953-958. doi:10.1212/01. wnl.0000269672.17807.e0

5. Centers for Disease Control and Prevention (1998) Summary of notifiable diseases, United States, 1997. MMWR Morb Mortal Wkly Rep 46:3-87

6. Steere AC, Berardi VP, Weeks KE, Logigian EL, Ackermann R (1990) Evaluation of the intrathecal antibody response to Borrelia burgdorferi as a diagnostic test for Lyme neuroborreliosis. J Infect Dis 161:1203-1209. doi:10.1093/infdis/161.6.1203

7. Aguero-Rosenfeld ME, Wang G, Schwartz I, Wormser GP (2005) Diagnosis of lyme borreliosis. Clin Microbiol Rev 18:484-509. doi:10.1128/CMR.18.3.484-509.2005

8. Hammers-Berggren S, Hansen $\mathrm{K}$, Lebech AM, Karlsson M (1993) Borrelia burgdorferi-specific intrathecal antibody production in neuroborreliosis: a follow-up study. Neurology 43:169-175

9. Kruger H, Reuss K, Pulz M, Rohrbach E, Pflughaupt KW, Martin R, Mertens HG (1989) Meningoradiculitis and encephalomyelitis due to Borrelia burgdorferi: a follow-up study of 72 patients over 27 years. J Neurol 236:322-328. doi:10.1007/BF00314373

10. Rupprecht TA, Pfister HW, Angele B, Kastenhauer S, Wilske B, Koedel U (2005) The chemokine CXCL 13 (BLC): a putative diagnostic marker for neuroborreliosis. Neurology 65:448-450

11. Senel M, Rupprecht TA, Tumani H, Pfister HW, Ludolph AC, Brettschneider J (2010) The chemokine CXCL13 in acute neuroborreliosis. J Neurol Neurosurg Psychiatry 81:929-933. doi: 10.1136/jnnp.2009.195438

12. Sipe JC, Knobler RL, Braheny SL, Rice GP, Panitch HS, Oldstone MB (1984) A neurologic rating scale (NRS) for use in multiple sclerosis. Neurology 34:1368-1372

13. Wilske B, Fingerle V, Schulte-Spechtel U (2007) Microbiological and serological diagnosis of Lyme borreliosis. FEMS Immunol Med Microbiol 49:13-21. doi:10.1111/j.1574-695X.2006.00139.x

14. Reiber H, Felgenhauer K (1987) Protein transfer at the blood cerebrospinal fluid barrier and the quantitation of the humoral immune response within the central nervous system. Clin Chim Acta 163:319-328. doi:10.1016/0009-898(87)90250-6

15. Kaiser R, Lücking CH (1993) Intrathecal synthesis of specific antibodies in neuroborreliosis. Comparison of different ELISA techniques and calculation methods. J Neurol Sci 118:64-72. doi: 10.1016/0022-510X(93)90247-V

16. Reiber H, Lange P (1991) Quantification of virus-specific antibodies in cerebrospinal fluid and serum: sensitive and specific detection of antibody synthesis in brain. Clin Chem 37:1153-1160

17. Reiber H (2005) Proteindiagnostik. In: Zettl U, Lehmnitz R, Mix E (eds) Klinische Liquordiagnostik, 2nd edn. Walter de Gruyter, New York, pp 177-248

18. Tumani H, Nölker G, Reiber H (1995) Relevance of cerebrospinal fluid variables for early diagnosis of neuroborreliosis. Neurology 45:1663-1670

19. Christen HJ, Hanefeld F, Eiffert H, Thomsen R (1993) Epidemiology and clinical manifestations of Lyme-Borreliosis in childhood-A prospective multicentre study with special regard of neuroborreliosis. Acta Paediatr Scand 82:1-75. doi:10.1111/ j.1651-2227.1993.tb18082.x

20. Lebech AM, Hansen K, Brandrup F, Clemmensen O, HalkierSørensen L (2000) Diagnostic value of PCR for detection of Borrelia burgdorferi DNA in clinical specimens from patients with erythema migrans and Lyme neuroborreliosis. Mol Diagn 5:139-150

21. Coyle PK, Schutzer SE, Deng Z, Krupp LB, Belman AL, Benach JL, Luft BJ (1995) Detection of Borrelia burgdorferi-specific antigen in antibody-negative cerebrospinal fluid in neurologic Lyme disease. Neurology 45:2010-2015

22. Hansen K, Lebech AM (1991) Lyme neuroborreliosis: a new sensitive diagnostic assay for intrathecal synthesis of Borrelia 
burgdorferi-specific immunoglobulin G, A, and M. Ann Neurol 30:197-205. doi:10.1002/ana.410300212

23. Steere AC (1993) Seronegative Lyme disease. JAMA 270:1369. doi:10.1001/jama.1993.03510110111042

24. Baig S, Olsson T, Hansen K, Link H (1991) Anti-Borrelia burgdorferi antibody response over the course of Lyme neuroborreliosis. Infect Immun 59:1050-1056

25. Cepok S, Zhou D, Vogel F, Rosche B, Grummel V, Sommer N, Hemmer B (2003) The immune response at onset and during recovery from Borrelia burgdorferi meningoradiculitis. Arch Neurol 60:849-855
26. Bannwarth A (1941) Chronische lymphozytäre meningitis, entzündliche polyneuritis and rheumatismus. Arch Psychaitr Nervenkr 113:284-376

27. Myglanda A, Ljøstada U, Fingerled V, Rupprecht T, Schmutzhard E, Steiner I (2010) EFNS guidelines on the diagnosis and management of European Lyme neuroborreliosis. Eur J Neurol 17:8-16. doi:10.1111/j.1468-1331.2009.02862.x

28. Pfister HW, Rupprecht TA (2006) Clinical aspects of neuroborrelisis and post-Lyme disease syndrome in adult patients. Int $\mathrm{J}$ Med Microbiol 40:11-16. doi:10.1016/j.ijmm.2005.12.003 